\title{
Clinical presentations of Ehlers Danlos syndrome type IV
}

\author{
F M POPE,${ }^{*}$ P NARCISI, ${ }^{*}$ A C NICHOLLS, ${ }^{*}$ M LIBERMAN,${ }^{*}$ AND J W E OORTHUYS $\ddagger$ \\ ${ }^{*}$ Medical Research Council, Clinical Research Centre, Harrow and $\ddagger$ Academisch Medisch Centrum, \\ Amsterdam, The Netherlands
}

SUMMARY Ehlers Danlos syndrome type IV is an often lethal disease caused by various mutations of type III collagen genes. It presents in infancy and childhood in several ways, and the symptoms and signs include low birth weight, prematurity, congenital dislocation of the hips, easy inappropriate bruising (sometimes suspected as child battering), and a diagnostic facial phenotype. These features predict a lethal adult disease often complicated by fatal arterial rupture in early or middle adult life. Most affected patients can be diagnosed from radiolabelled collagen protein profiles by polyacrylamide gel electrophoresis. Prenatal diagnosis by specific type III collagen restriction fragment length polymorphisms is possible in some families, and will become increasingly important. Prenatal diagnosis and prevention of the disease in selected families is already possible and will be widely available in the future.

Ehlers Danlos syndrome is an heterogeneous disorder of connective tissue characterised by abnormalities in the skin, ligaments, the pleuroperitoneal linings of the gastrointestinal tract, and the cardiovascular system. Of more than nine different forms of the disease type IV is particularly dangerous, often being complicated by lethal rupture of small and medium sized arteries later in life. ${ }^{1}$ First described by Barabas ${ }^{2}$ as the arterial type, and Beighton $^{3}$ as the ecchymotic variant of Ehlers Danlos syndrome, specific molecular abnormalities were first identified in $1975 .{ }^{4}$ The clinical range is wide and there are autosomal dominant and recessive forms of the disease. The so called 'acrogeric' form has a much worse prognosis than the ecchymotic form which probably has some degree of overlap with the Ehlers Danlos syndrome type I syndrome. ${ }^{1}$ With the advent of recombinant deoxyribonucleic acid (DNA) technology, and advances in molecular biology, the gene for human type III collagen has been cloned firstly as a cDNA covering the $3^{\prime}$ end, ${ }^{5}$ and more recently as full genomic sequences. ${ }^{6}$ At least two restriction fragment length polymorphisms have been identified with which the mutant locus can be traced in suitable families. The way is therefore open for prenatal diagnosis and prevention of this disease, and because it often presents in childhood in a diverse and sometimes remarkable fashion we describe here the essential physical attributes as seen in infancy, childhood, and adolescence by paediatricians, rheumatologists, dermatologists, geneticists, and general practitioners. Sometimes these patients present first as new mutations, and at other times as members of affected families in which the disease has already been diagnosed in adults. Some patients presented to us in childhood, but in others the childhood history and clinical photographs of the adults were sufficiently interesting and relevant that we have included them.

\section{Case reports}

CASE 1

A boy was born prematurely at 35 weeks' gestation weighing less than $2000 \mathrm{~g}$. He had a cerebral 의 haemorrhage, and then developed hydrocephalus. $\supset$ At birth he had a tight amniotic band deforming his right lower leg. His mother subsequently died at the age of 30 after a massive retroperitoneal haemor- $\sigma$ rhage from a ruptured aorta. Photographs of the $\tilde{N}$ mother showed the typical features of acrogeric $\underset{\omega}{\mathrm{N}}$ Ehlers Danlos syndrome type IV with large eyes and 0 peaked nose, and premature aging of the hands (acrogeria).

Examination of radiolabelled collagens from the $\stackrel{\mathscr{P}}{?}$ child's cultured skin fibroblasts showed the typical 0 profile of acrogeric Ehlers Danlos syndrome type IV (fig 1). The mother was the tenth of 11 children and 


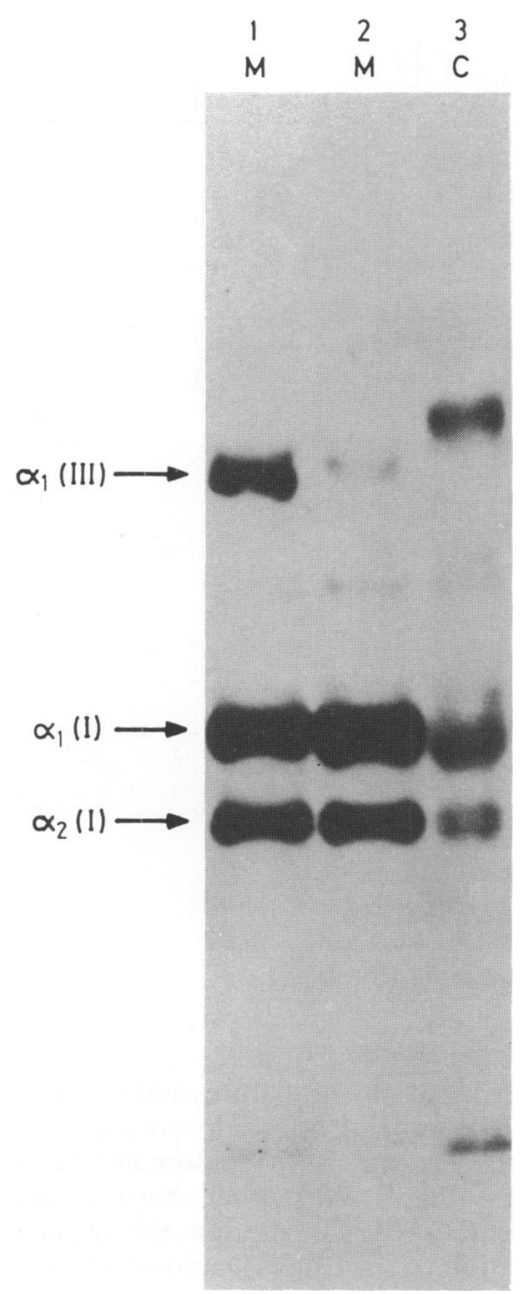

Fig 1 Radiolabelled ${ }^{14} \mathrm{C}$ labelled collagen profile of case 1. Note intracellular retention and poor secretion of the mutant protein in tracks 2 and 3 compared with normal control in track 1 .

had normal parents and siblings. Her father was 43 years old when she was born, and presumably the gene defect transmitted to her son was a new autosomal dominant mutant.

\section{CASE 2}

A girl was delivered by caesarean section (because of abruptio placentae and fetal distress) at 38 weeks' gestation of her mother's first pregnancy; she weighed $2005 \mathrm{~g}$. Her parents were second cousins. At birth she was noted to have unusual facies, dislocated right shoulder and hip and scanty subcutaneous fat. She subsequently failed to thrive, developed serious feeding difficulties, and was transferred to Great Ormond Street hospital. An electroencephalogram showed an abnormal focal disturbance, and subsequent epileptic fits were reasonably well controlled with phenobarbitone. Chromosomes showed a normal 46XY karyotype. Her feeding difficulties were partially caused by a hiatus hernia and a malrotated stomach.

She had extremely thin and soft atrophic skin with a prominent venous pattern (fig 2). Her joints dislocated easily, especially the hips and the shoulders, and her feet were long and looked somewhat delicate. She subsequently developed severe gastroenteritis and died. Necropsy was not done.

\section{CASE 3}

A baby boy was born prematurely at 30 weeks' gestation after premature rupture of the membranes. He was the youngest of four children with completely normal siblings and parents. He had bilateral dislocation of the hips that responded well to conservative splinting. He was also noted to have generally thin skin and long, delicate fingers and toes that were somewhat hyperextensible, a phenotype similar to case 2 (fig 3a). When next seen (at the age of 18 months) he was in hospital because of excessive, unexplained, persistent bruising. Examination showed the typically large eyes and pinched nose of acrogeric Ehlers Danlos syndrome type IV (fig $3 b$ ). Except for being slow to walk he was otherwise physically normal. Because of his parents' extreme anxiety he has not been followed up regularly but at the time of writing had developed no further complications.

\section{CASE 4}

A 3 year old boy was referred with suspected Ehlers Danlos syndrome type IV. His mother had joint laxity, anorexia nervosa, and a history of spontaneous rupture of the anterior tibial artery. The history was complicated by suspected battering of the child by his father and he had been admitted to the local paediatric department at the age of 2 months with a fractured shin, a large right parietal bruise, and a subdural haematoma. He also had fractures of the lower end of the left tibia and fibula, and excessive bruising of his neck and face. Subsequently he showed some developmental delay and at the age of 21 months had an estimated developmental age of 14 months and a speaking age of 9 months. Having weighed only $2500 \mathrm{~g}$ at birth, he remained close to the 50th percentile for weight.

When examined at the age of 3 he showed clear physical characteristics of Ehlers Danlos syndrome with a broad forehead and feet and obvious joint 


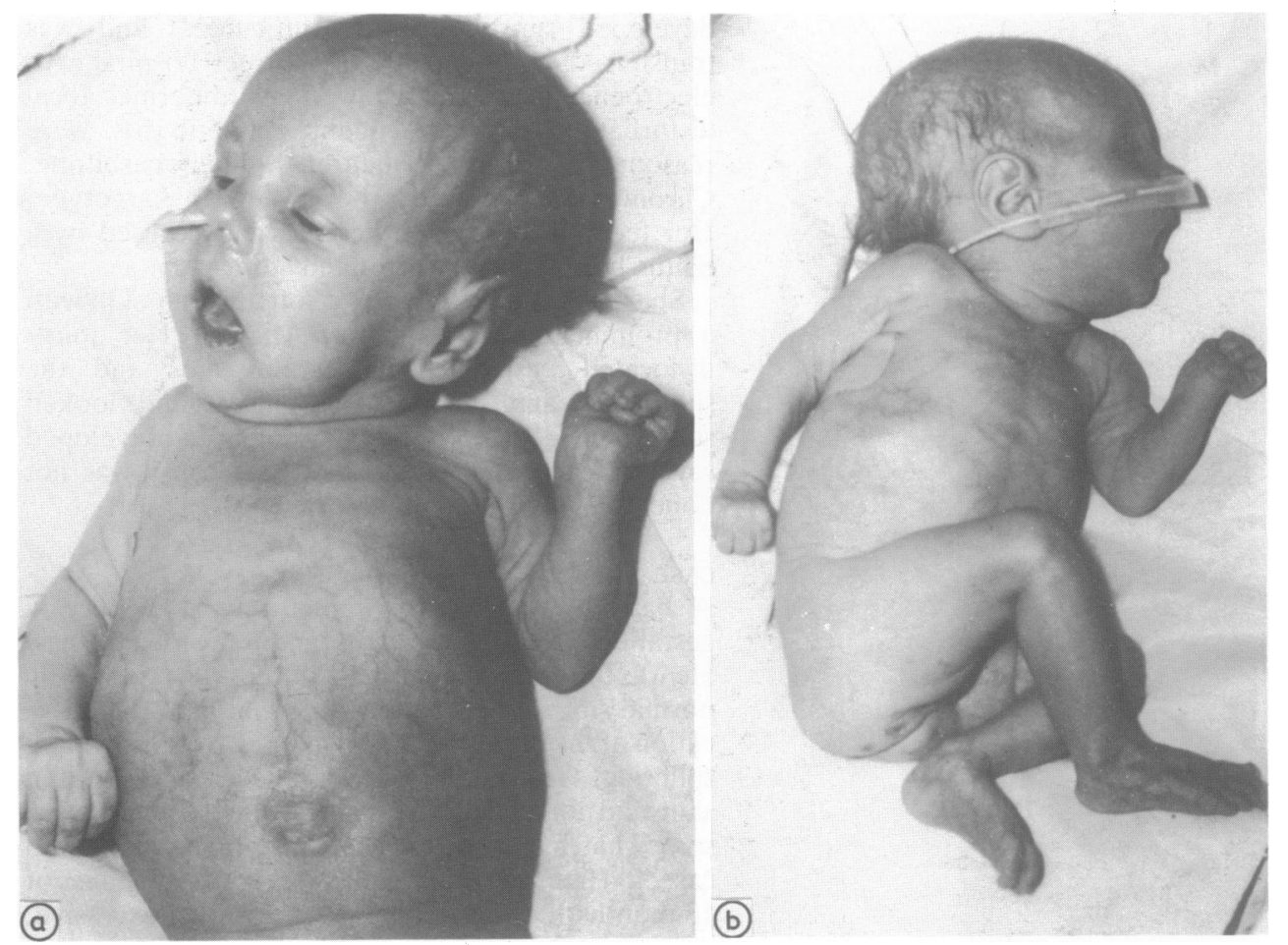

Fig 2 Case 2: note generally thin wrinkled skin with prominent venous network, and long delicate feet.

hypermobility (figs 4a and 5a and b). We did not consider his facial features diagnostic of acrogeric Ehlers Danlos syndrome (case 1) but provisionally classified him as type II or III Ehlers Danlos syndrome. Subsequent investigations clearly placed him in the Ehlers Danlos syndrome type IV group. Firstly, cultured skin fibroblasts showed typical failure to secrete type III collagen into the medium with retention of a slightly higher molecular weight molecule in the cell layer (fig 6). Clinical photographs of his mother's face and hands (figs $4 \mathrm{~b}$ and 5c) showed unmistakable acrogeric (lethal) Ehlers Danlos syndrome type IV. Clearly this gene had been inherited as an autosomal dominant, but presented atypically in childhood.

\section{CASE 5}

A 7 year old girl was referred by a dermatologist to whom she had been sent for assessment of nonhaematological bruising and a suspected history of non-accidental injury. She had bruises on the limbs and trunk and poorly healed scars on her legs. Her skin was transparent with clearly visible superficial capillary and venous systems. She also had a thin nose and lips, and large prominent eyes. Her
13 year old brother had similar features and was also clearly recognisable as being affected from a photograph taken at the age of 2 . Both children had been small babies (less than $3000 \mathrm{~g}$ when born at full term). Their mother (fig 7) showed the typical clinical features of acrogeric Ehlers Danlos syndrome type IV, without serious complications except for flexion contractures of the interphalangeal joints of her hands, and severely clawed feet as a result of tendon contractures causing flexion deformities of the metatarsophalangeal joints. Her facial features in childhood (fig 7a) had been identical to theirs; there was no other relevant family history.

\section{CASE 6}

A 9 year old boy presented incidentally when we examined his mother who had typical acrogeric Ehlers Danlos syndrome type IV. He had weighed $2900 \mathrm{~g}$ when born at full term and up to the time of examination had had no problems. He had two normal elder siblings. He also was clearly recognisable as having Ehlers Danlos syndrome type IV. His mother subsequently had an operation for rectal prolapse, ruptured her iliac artery and vein, and died. 

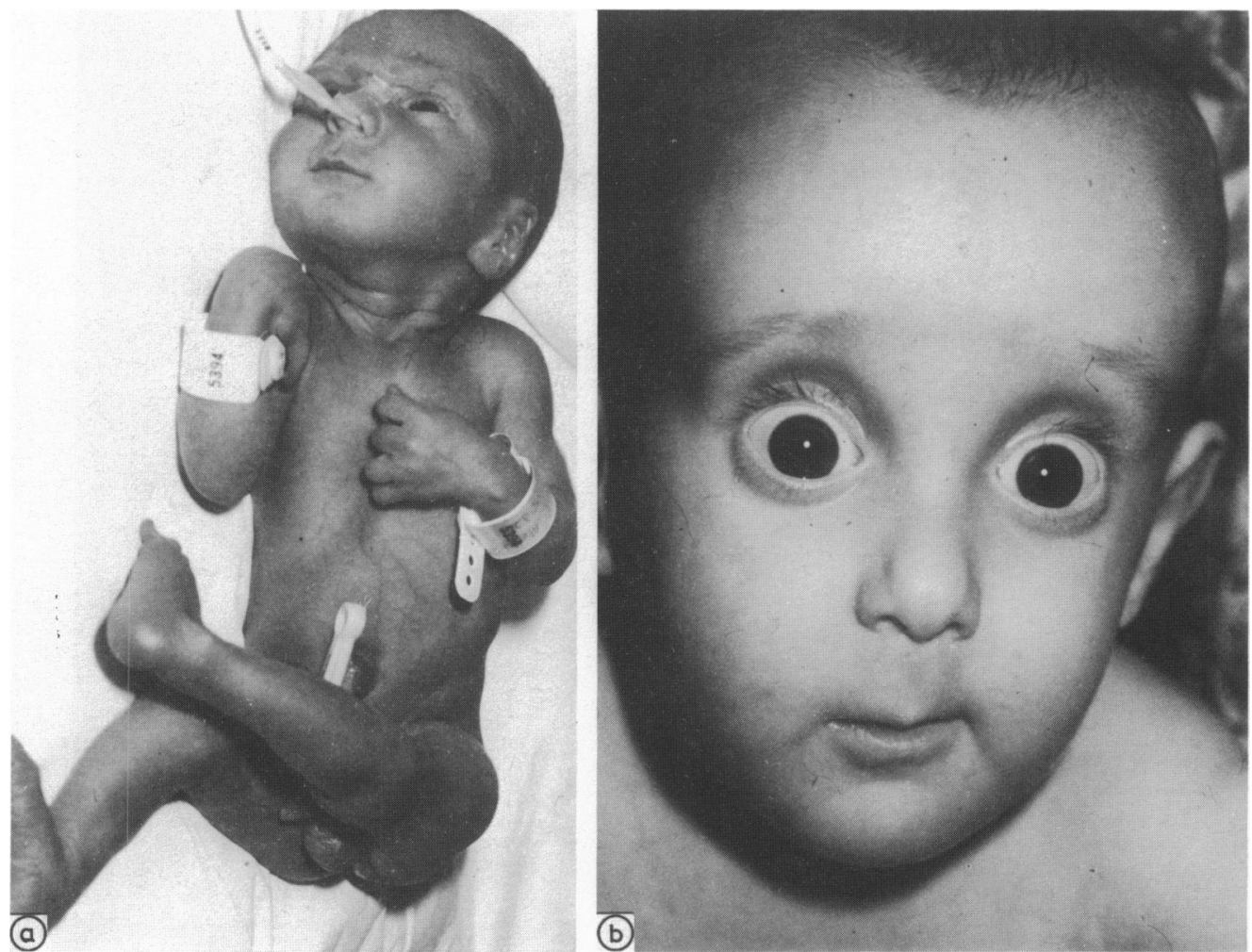

\section{CASE 7}

An 8 year old girl presented in 1979 to the local hospital with a history of persistent bruising since childhood. Detailed haematological examination was normal and she showed features suggestive of the Ehlers Danlos syndrome. When examined by us she did not show the facial features of acrogeric Ehlers Danlos syndrome type IV but had large eyes and thin skin. Her father, who had a history of bilateral recurrent pneumothoraces, also had thin skin prominent varicose veins, hypermobility of the joints, and large eyes. Neither patient has had any further problem at the time of writing, even though their tissues contained only traces of type III collagen and produced little from cultured skin fibroblasts.

\section{CASE 8}

A Cretan girl presented as a teenager with a history of having bruised easily and been loose jointed from the age of 3 . She had weighed $3400 \mathrm{~g}$ at birth, the pregnancy had been normal. Noticeable clinical features included large, prominent eyes with blue sclerae similar to those in cases 4 and 6 . Unlike them she showed extensive haemosiderotic staining of the anterior shins (figs 8a, b, c, and d). She had rather prominent capillary telangiectasia, and prominent venules over her upper anterior chest. Her otherwise normal mother had loose jointed fingers and a lax lumbar spine. Radiolabelled collagens from both mother and daughter showed somewhat diminished type III collagens (fig 8e) secreted into the medium (these were about $60-70 \%$ of the expected control secretions). In contrast to the acrogeric pattern of Ehlers Danlos syndrome, there was no abnormality of collagen secretion.

CASE 9

An unusual 11 year old girl was referred by a geneticist with a history of persistently low weight and short stature. She had continued below the 3rd centile and skeletal dysplasia had been suspected (particularly the Leri-Weil syndrome). Another unusual feature was rather sparse scalp hair, but in 

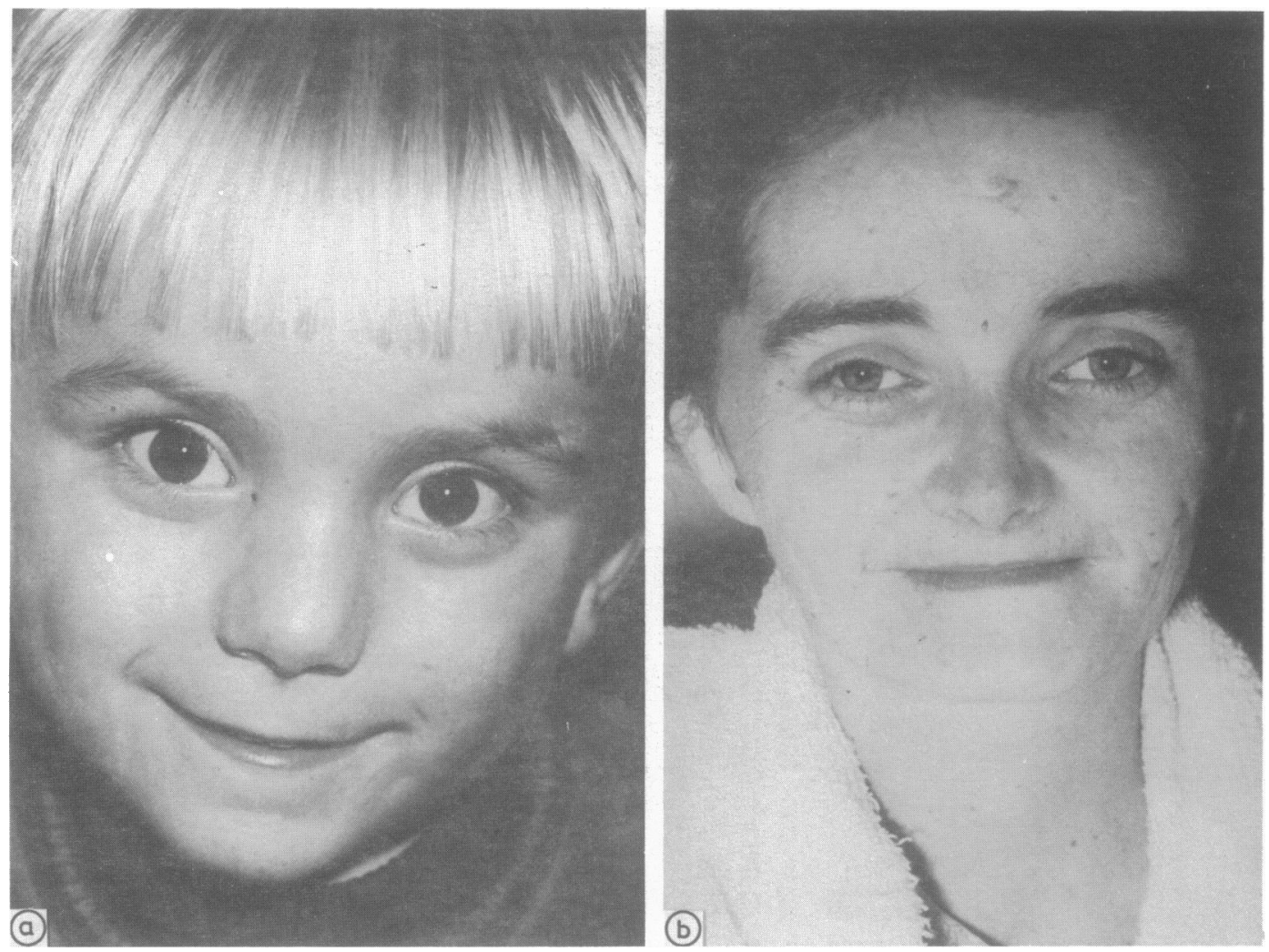

Fig 4a Face of case 4 showing broad forehead more suggestive of Ehlers Danlos syndrome type I or II. Fig 4b Mother of case 4: facial phenotype is clearly that of acrogeric Ehlers Danlos syndrome type IV.

other respects she had typical Ehlers Danlos syndrome type IV. Collagen analysis showed type III collagen deficiency without retention.

\section{CASE 10}

A 9 year old girl was born weighing $2800 \mathrm{~g}$ at 37 weeks' gestation. Her mother immediately suspected an abnormality and subsequently the child persistently bruised easily. Acrogeria was diagnosed by her local dermatologist. Examination at the age of 10 confirmed typical acrogeric Ehlers Danlos syndrome type IV. Her cultured fibroblasts made no type III collagen (as measured by carboxymethyl cellulose chromatographs of radiolabelled collagens). At the time of writing she was of childbearing age, and anxious to have accurate genetic counselling.

\section{CASE 11}

This 6 year old girl was the third generation of her family to be affected with acrogeric Ehlers Danlos syndrome type IV. Though many family members had died of the arterial complications of the disease, hers was biochemically atypical. Measurement of type III collagen showed a $10-20 \%$ reduction in the quantity of normally sized protein. Subsequently we studied the familial segregation of a collagen ava II restriction fragment length polymorphism using a $3^{\prime}$ human type III cDNA as probe. This accurately predicted the disease and will be used in future for prenatal diagnosis and prevention in this family.

The patient's abnormal physical signs included large eyes, a pinched nose, and a tendency to bruise abnormally. The phenotype of her adult family was similar. At the time of writing the child had developed no complications but undoubtedly she is at high risk of spontaneous arterial rupture in early middle age.

CASE 12

A 13 year old girl presented to the casualty department of her local hospital in The Netherlands with a migrainous headache. This resolved but shortly afterwards she had a transient left hemiplegia. An emergency arteriogram showed an 'in and out' 

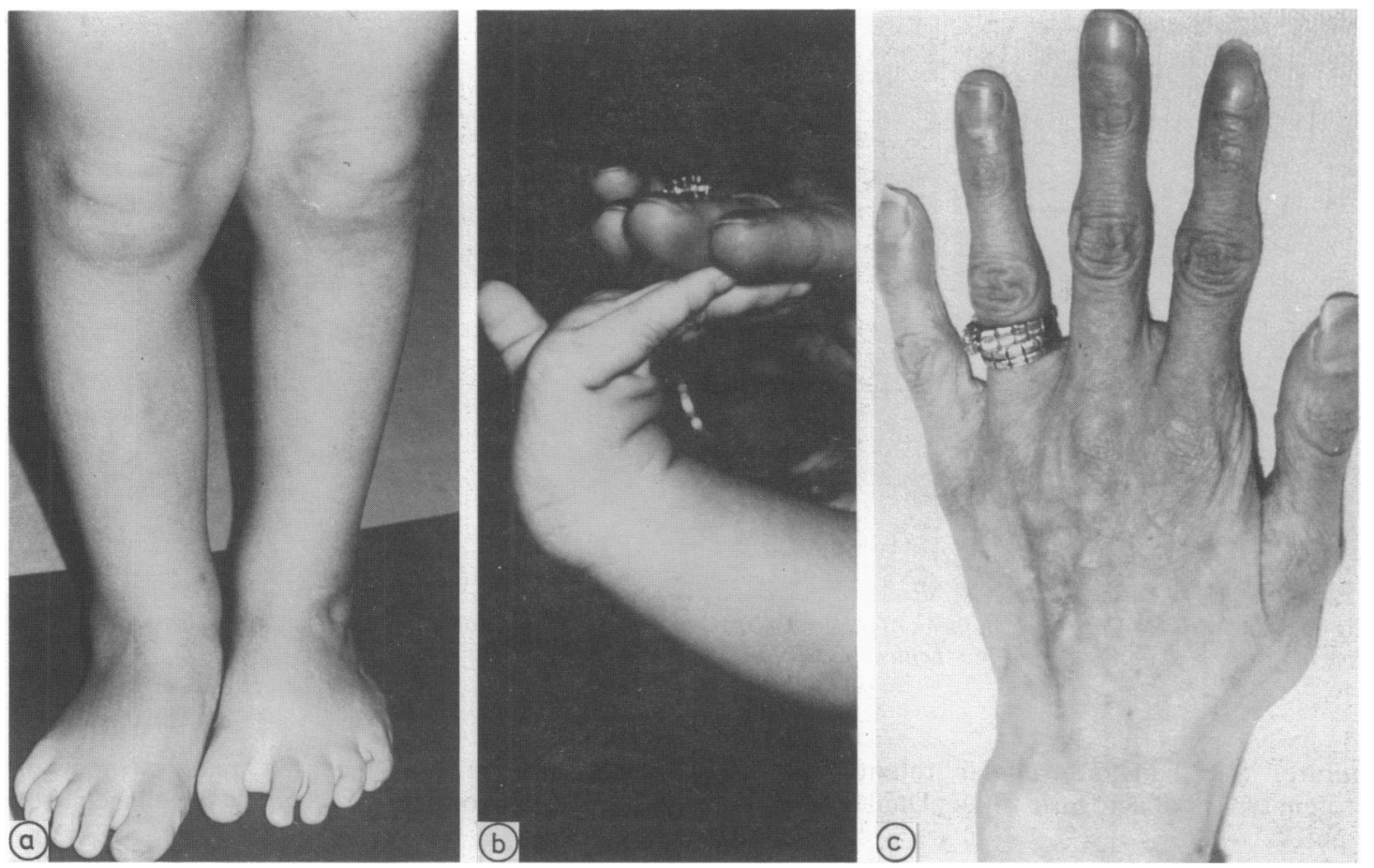

Fig 5a and b Broad feet and loose jointed hands of case 4. Fig 5c Acrogeric hands of mother of case 4.

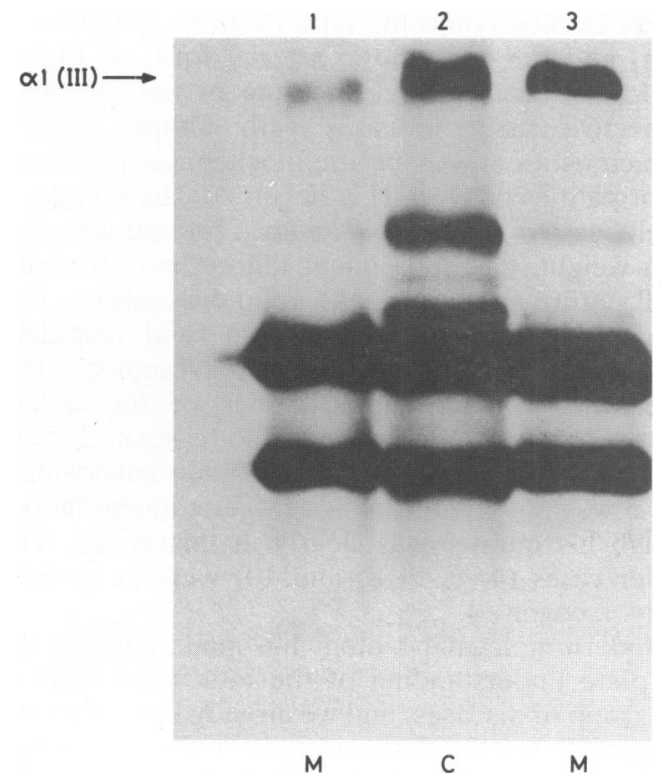

dissection of the right internal carotid artery, and a computed tomogram showed partial necrosis of her right internal capsule. She made a complete recovery without residual signs. Physical examination showed the classical facies of acrogeric Ehlers Danlos syndrome type IV with large eyes, a pinched nose, and a madonna-like facies. Photographs taken when she was a baby clearly showed a recognisable phenotype. The biochemical investigations show a $50 \%$ reduction of type III collagen without intracellular retention, which clearly distinguishes her from the usual acrogeric pattern.

CASE 13

A 33 year old woman died of an undiagnosed rupture of the splenic artery having been treated conservatively for suspected cholecystitis. Previous events had included a ruptured liver after the birth of her only normal child, though no severe problems had arisen during the pregnancy. Examination of childhood photographs show the diagnosis to be quite obvious in babyhood and childhood as well as in adult life (figs 9a, b, and c). Silver-Russell dwarfism had been suspected as she had always been a small child (below the 3rd percentile for height and weight). Biochemical investigation showed no type III collagen contained in tissue or produced in

Fig 6 Radiolabelled collagens from case 4 separated in $5 \%$ polyacrylamide slab gels. Note poor secretion and abnormal retention (tracks 1 and 2) compared with normal control (track 3), which is typical of acrogeric Ehlers Danlos syndrome type IV. 

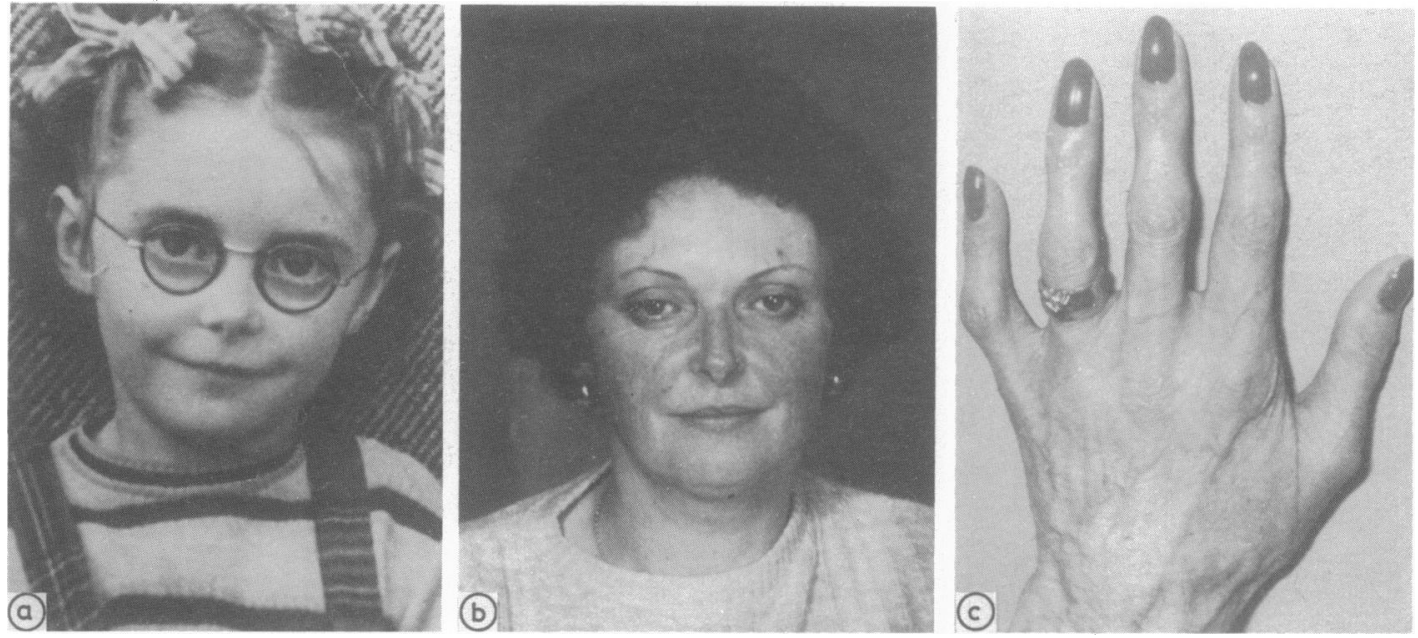

Fig 7a and b Childhood and adult facies of mother of case 5 showing typical acrogeric Ehlers Danlos syndrome type IV: note large eyes and thin nose. Fig 7c Typical prematurely aged hand of case 5.

culture. She had intracellular retention of the protein typical of acrogeric Ehlers Danlos syndrome type IV.

CASE 14

A girl aged 7 was described to the Section of Paediatrics of the Royal Society of Medicine as an example of acrogeria. ${ }^{7}$ Her photographs at the time showed the typically thin skin and facies of acrogeric Ehler Danlos syndrome type IV (figs 10a and b). Her subsequent history has included recurrent bilateral pneumothoraces (treated by pleural stripping), a spontaneously ruptured spleen, and a ruptured left renal artery that was treated by nephrectomy. She also had a miscarriage at 16 weeks' gestation of her only pregnancy. Other complications included severe shortening of the right achilles tendon causing severe talipes equinovarus. At the time of writing she was 37 years old and had had no other serious complications. Her biochemical investigations showed a typical failure to secrete type III collagen that is retained in abnormal quantities intracellularly.

\section{CASE 15}

A young man died at the age of 16 of a ruptured aorta with dissection upwards into the subclavian artery and downwards in the abdominal aorta below the renal artery. He had the classical features of acrogeric Ehlers Danlos syndrome type IV with the typical facies and profile of the disease (figs 11a and b). Detailed investigation of the family showed the autosomal recessive segregation of type III collagen deficiency. He was the first patient in whom molecular abnormalities of type III collagen were described. ${ }^{48}$

\section{Discussion}

Ehlers Danlos syndrome type IV (also called acrogeria, and the ecchymotic arterial form of Ehlers Danlos syndrome) is clearly one of the inherited connective tissue diseases with unique clinical characteristics and a specific biochemical profile of abnormalities of type III collagen. ${ }^{89}$ The disease is usually easily recognisable and can present with low birth weight, and subsequent failure to thrive with small stature and low weight. Joint dislocations, and severe bruising with thin skin and capillary prominence or telangiectasia, are common. The facies and general characteristics of the severe acrogeric pattern are unmistakable (cases 1, 2, 5, 9, $11,12,13,14,15,16$, and 17). Rather surprisingly case 3 was not diagnosed as acrogeric in childhood, though his mother was clearly in this group. The milder cases $(4,6,7,8$, and 10$)$ were in general easily recognised.

Modern molecular biology has made possible the $\tilde{N}$ complete understanding of the molecular basis of $\underset{\omega}{N}$ this group of diseases, and we already know that the acrogeric group (with intracellular retention and no $o$ secretion of type III collagen) are different from the $\stackrel{\odot}{\Phi}$ ecchymotic group (who usually produce diminished $\stackrel{\oplus}{+}$ amounts of normally secreted protein that is not 0 retained intracellularly). Case 13 is exceptional in having an ecchymotic biochemical profile but the 

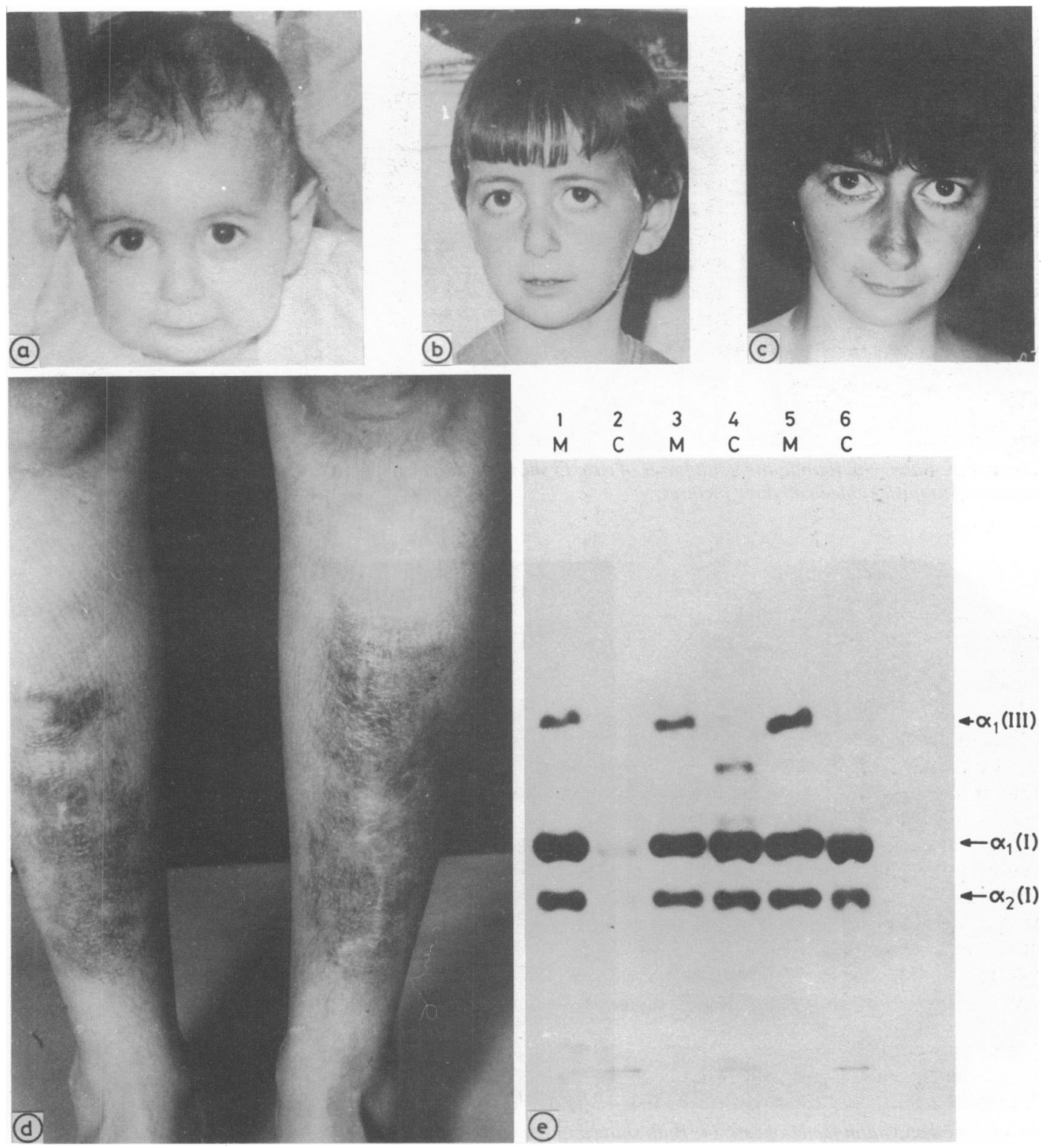

Fig 8a, b, and c Baby, childhood and adolescent facies of case 8. Fig 8d Pretibial ecchymoses in adolescence (case 8). Fig 8e Biochemical changes (case 8) show only lowered medium collagens tracks 1 and 3 compared with control in track 5. Neither patient nor control (tracks 2, 4, and 6) retain radiolabelled material intracellularly.

acrogeric (vascular rupture) phenotype. Probably all patients deficient in type III collagen are at risk of vascular rupture, but this is invariable and often fatal in the acrogeric group.

The gene for human type III collagen has been cloned both as cDNAs for the $3^{\prime}$ and $5^{\prime}$ ends and as long genomic fragments. ${ }^{56}$ At the time of writing two protein mutations had been identified in patients with Ehlers Danlos type IV. The first produces a site abnormally susceptible to pepsin in what seems to be a lengthened protein ${ }^{10}$; the second produces a large deletion that results in a mutant protein of $5 / 7$ 

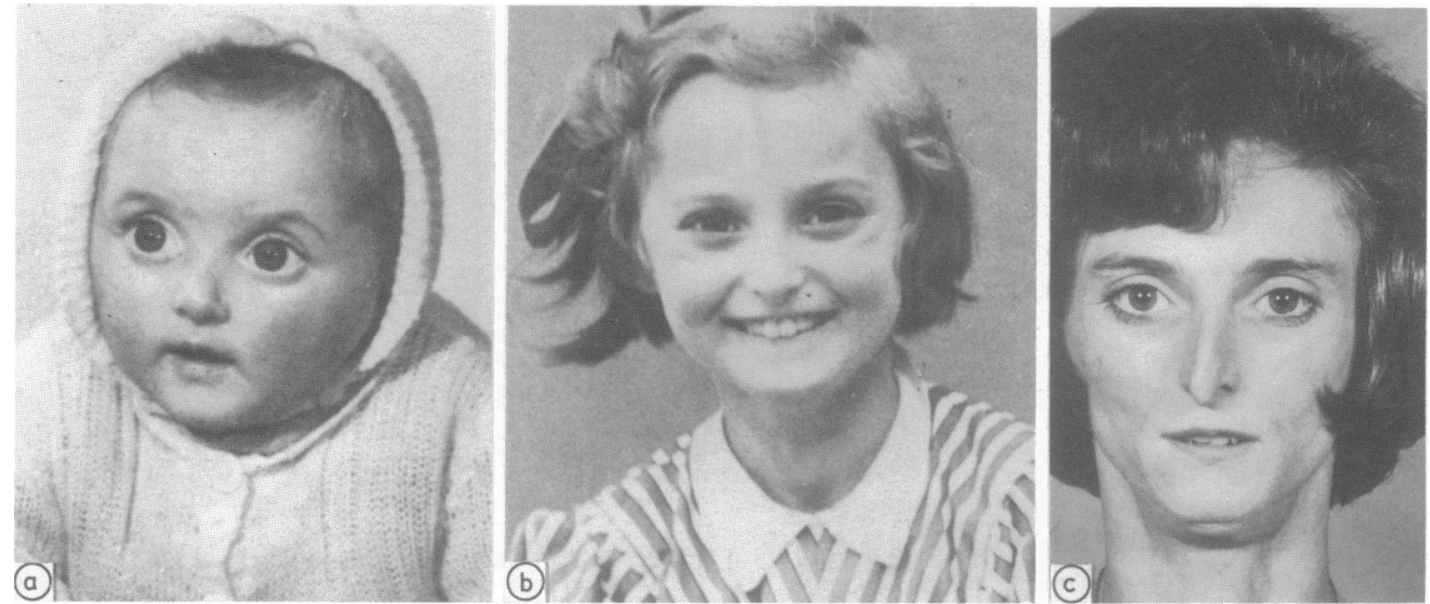

Fig 9a, b, and c Baby, childhood, and adult facies of case 13 showing typical acrogeric Ehlers Danlos syndrome type IV. The diagnosis is unmistakable in all three pictures.
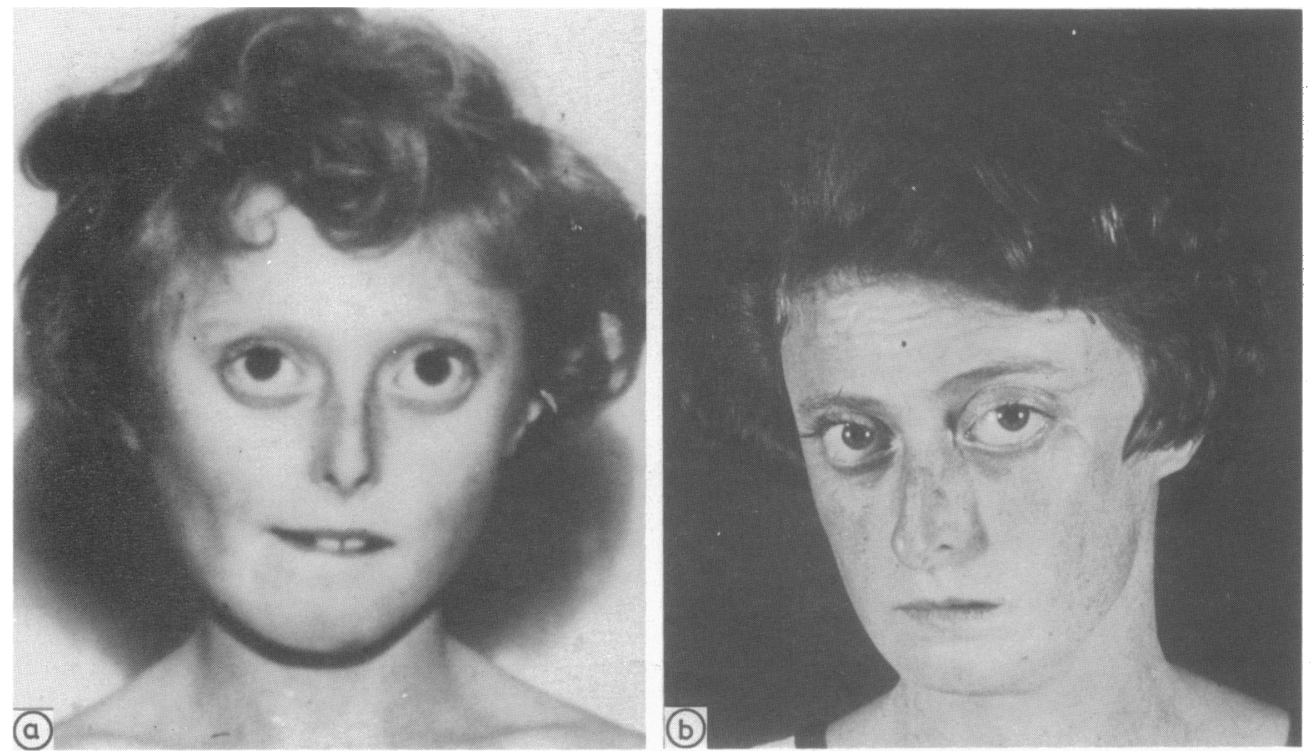

Fig 10 Childhood and adult facies of case 14. Both show unmistakable acrogeric Ehlers Danlos syndrome type IV. The childhood photograph was originally published in 1957."

the normal size, and a large deletion in mRNA and genomic DNA seen on Northern and Southern blotting. ${ }^{11}$ So far we have found only quantitative abnormalities in type III collagen mRNA (in case 13) and no evidence of major deletions. Probably the mutations causing the obvious protein abnormalities are subtle and therefore difficult to detect, but recent rapid advances in molecular biological 

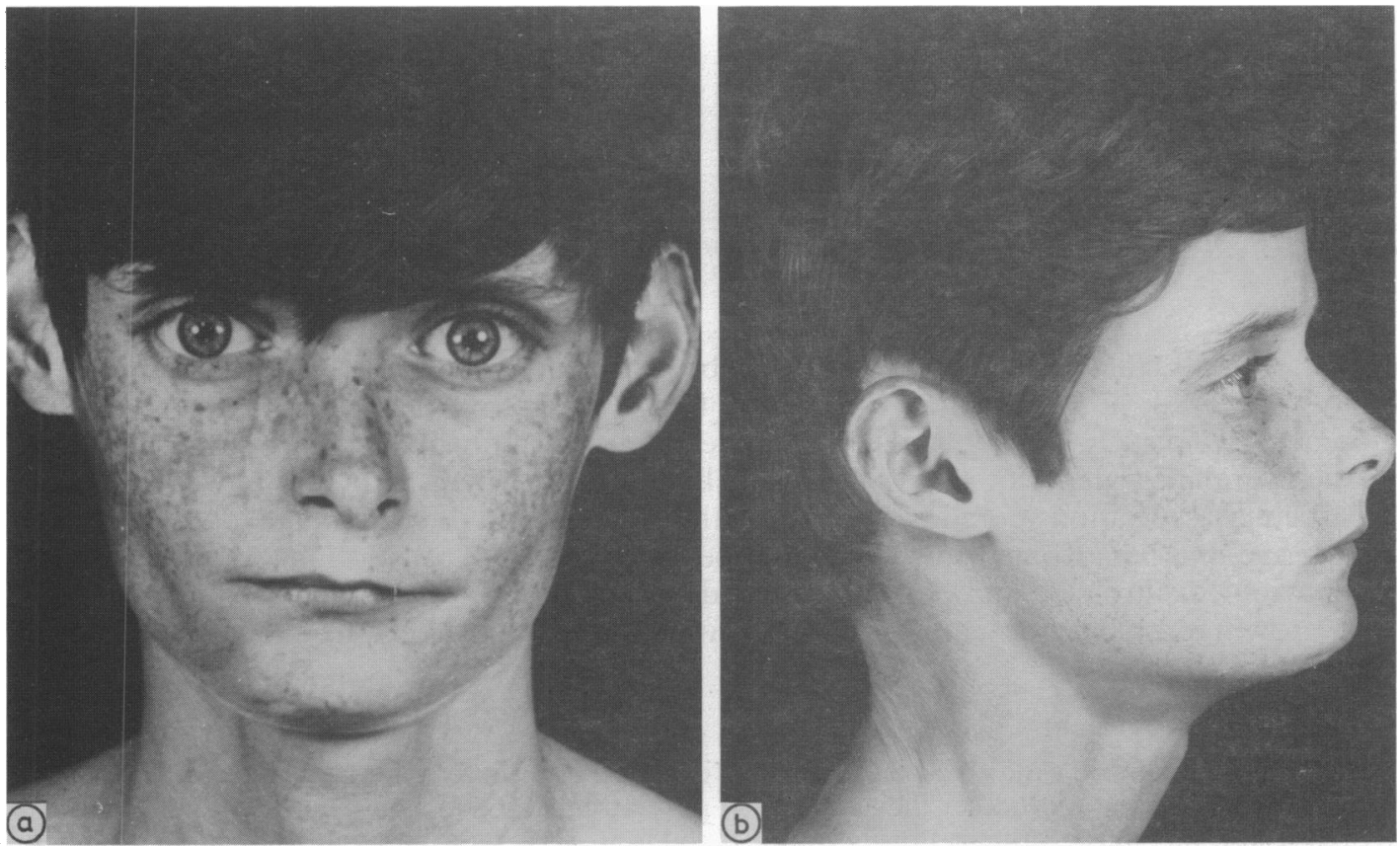

Fig 11 Front face and profile of first patient with acrogeric Ehlers Danlos syndrome type IV in whom type III collagen deficiency was discovered.

and Dupre's original patient was identical to those patients with acrogeric Ehlers Danlos syndrome type IV (figs 6, 7, 9, 10, and 11).

The differential diagnosis includes other forms of Ehlers Danlos syndrome, especially types I, II, III, and VII. Type VII may be completely separated on clinical grounds and the persistence of procollagen extension sequences produced in culture or contained in tissues that are resistant to pepsin. The specific finding of type III collagen mutations exclude the other types, so that type III collagen mutations stand apart both clinically and biochemically.

\section{References}

${ }^{1}$ McKusick VA. Mendelian inheritance in man. Catalogues of dominant autosomal recessive, and $X$-linked phenotypes. 7th ed. Baltimore: John Hopkins University Press, 1986.

2 Barabas A. Vascular complications with Ehlers Danlos syndrome with special reference to the arterial type of Sacks syndrome. J Cardiovasc Surg 1972;13:160-7.

${ }^{3}$ Beighton P. The Ehlers Danlos syndrome. London: William Heinemann Medical Books, 1970.

4 Pope FM, Martin GR, Lichtenstein JR, et al. Patients with Ehlers Danlos syndrome lack type III collagen. Proc Natl Acad Sci USA 1975:72:1314-6.
${ }^{5}$ Loidl HR, Brinker JM, May M, et al. Molecular cloning and carboxylpeptide analysis of human type III procollagen. Nucleic Acids Res 1984;12:9383-94.

${ }^{6}$ Chu M-L, Weil D, de Wet W, Bernard M, Sippola M, Ramirez F. Isolation of cDNA genomic clones in coding human pro 1 (III) collagen. J Biol Chem 1985;260:4357-63.

${ }^{7}$ Morris D. Acrogeria. Proceedings of the Royal Society of Medicine 1957;50:330-1.

${ }^{8}$ Pope FM, Martin GR, McKusick VA. Inheritance of Ehlers Danlos type IV syndrome. J Med Genet 1977;14:200-4.

${ }^{9}$ Pope FM, Nicholls AC. Collagen genes and proteins in human disease. In: Chapman RH, ed. Recent advances in dermatology 7. Edinburgh: Churchill Livingstone, 1986:23-50.

${ }^{10}$ Stolle CA, Pyeritz RE, Myers JC, Prockop DJ. Synthesis of an altered type III procollagen in a patient with type IV Ehlers Danlos syndrome. J Biol Chem 1985;260:1937-44.

"Steinmann B, Superti Furga A. Dominant Ehlers Danlos type IV caused by mRNA type III collagen. J Med Genet 1987;24:636.

12 Gottron H. Familiäre Akrogerie. Archiv Dermatol Syphilis 1940;181:571-83.

13 Bazex A, Dupre A. Acrogeria (Type Gottron). (A propos d'une observation). Place de l'Acrogeria dans le cadre des atrophies cutanées congénitales. Ann Dermatol 1955;82:604-5.

Correspondence to Dr FM Pope, Medical Research Council Clinical Research Centre, Watford Road, Harrow, Middlesex HA1 3UJ.

Accepted 2 November 1987 